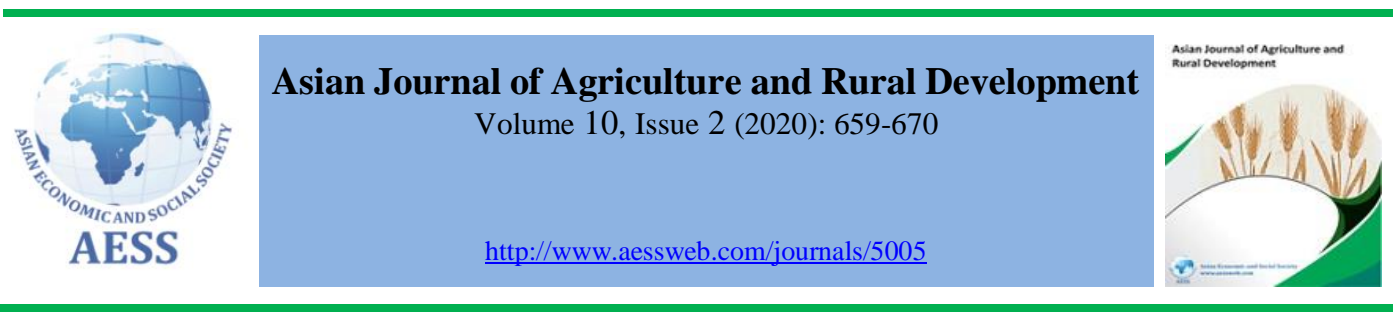

\title{
CHALLENGES FACING COMMUNITY PARTICIPATION IN PARTICIPATORY FOREST MANAGEMENT IN SOUTHWESTERN ETHIOPIA
}

Kero Department of Natural Resource Management, Wolaita Sodo Alemu Danano University, Ethiopia

kerobonga@gmail.co

\section{ARTICLE HISTORY: \\ Received: 18-Mar-2020 \\ Accepted: $30-\mathrm{Jul}-2020$ \\ Online Available: $02-$ Sep- 2020}

\section{Keywords:}

Community participation,

Sustainable,

Participatory Forest

Management,

Addiyo woreda

\begin{abstract}
The purpose of this paper remained to detect the Contests of the communal participation of participatory forest management in selected kebeles of Addiyo woreda, Kaffa zone of SNNPRS of Ethiopia. The study engaged main and subordinate data sources. The study sites were selected by using purposively, and sample respondents were selected by using systematic sampling techniques. Accordingly, 295(91 females and 204 males) households were selected. The household survey, FGD, personal observation, and key informant interviews were used for primary data collection. The data of the study had analyzed using both numerical and qualitative methods. Binary logistic regressions remained employed to evaluate factors affecting the participation of households in PFM. The study initiates that woodland coverage is decreasing, the logistic regression results revealed that participation in PFM has a statistically significant and negative relationship with annual income, the distance of households from the PFM site, and PFM site from the market, whereas a positive relationship with family size, forest income, number of livestock, awareness of households about PFM and support from external stakeholders. Therefore, to see sustainable participatory woodland managing in the study zone, awareness would remain created among communities for this government, and external stakeholders should work co-operatively and actively.
\end{abstract}

\section{Contribution/ Originality}

This paper is crucial for the scientific world by searching the challenges in inaccessible areas of the world and using the logistic regression model for analyzing the challenges on the application of participatory forest management. It also contributes to the community still depending on the traditional form of usage of firewood and more dependent on forests for their livelihood by creating more awareness in respect of the challenges in the application of participatory forest management wisely by evaluating it in different viewpoints.

DOI: 10.18488/journal.ajard.2020.102.659.670

ISSN(P): 2304-1455/ ISSN(E): 2224-4433

How to cite: Kero Alemu Danano (2020). Challenges facing community participation in participatory forest management in Southwestern Ethiopia. Asian Journal of Agriculture and Rural Development, 10(2), 659-670.

(C) 2020 Asian Economic and Social Society. All rights reserved. 


\section{INTRODUCTION}

Forests provide ecosystem services that serve as a source of employment, cultural and aesthetic uses, subsistence uses, and direct or indirect income. Nonetheless, in many cases, access to natural resources is neither uniform nor equitable within and between communities (Islam et al., 2013). Even though there is little documentation of history that shows communities' traditional resource management practices in Ethiopia, it is clear that several communities had traditional/indigenous resource management practices, including some elements of biodiversity conservation (Kanel and Dahal, 2008). Management of Forest varies in intensity from a leave alone, natural situation to a highly intensive regime with silvicultural interventions. Forest Management is generally increased in intensity to achieve either economic criteria (increased timber yields, non-timber forest products, ecosystem services) or ecological criteria (species recovery, fostering of rare species, carbon sequestration) to achieve these; local community plays a significant role in forest management and land-use decision making by themselves in the facilitating support of the government as well as change agents (Shindler et al., 1999). Globally many practices show that changes from statecentered policies toward clarifications at the native level, like PFM, resulted in property forest conservation and development to achieve sustainability (Fisher, 1999 and Khanal, 2007). Government inducing participation, presence of great indigenous knowledge on natural resources conservation by the community, perceived effects of forest degradation on their livelihoods, and perceived benefits of rehabilitation practices enabled the households to participate more in forest management, conservation and rehabilitation (Asfaw and Fekadu, 2018). Though, without the legal recognition of the right to use forest products, local people have neither the interest nor the courage in protecting and developing forests. Such systems would rather generate an incentive structure that forces locals to irresponsibly exploit forests (Dereje and Mulugeta, 2019). Supported from lessons learned elsewhere, participatory forest management (PFM) was introduced to an African country by some NGOs and donor agencies, notably the FARM continent, SOS Sahel, GTZ, and JICA (Temesgen, 2007). In biological science, management is to boost a method that desires continuous coordination among completely different sectors and cross-plane figure bodies. However, it desires to associate the correct guideline for a suitable implementation. Such a suggestion among national and regional environmental bodies would rely on the capability and temperament of the voters and also the society (Zewdie, 2002). As a result of it's threatening for a fish swimming at intervals the ocean to image a world while not water; therefore, it's tough for Kaffa individuals to image their lives while not forest. The forest has been a neighborhood for consumption, financial gain generation, and spirituality equally as \{a partial neighborhood an area district|a regional nativeity|a vicinity section \} for local establishments, data production, and power relationships. The generality of forests is to boost visible in their second leg to face agriculture (Stellmacher, 2007). Whereas knowing such a reality, the government has been attempting to implement completely diverse forest management methods overtime at intermissions the country. The Department of Agronomy has nominated fifty-eight of the forest as National Forest Priority areas (NFPAs) at the beginning of the Nineteen Eighties. The foremost objective behind the identification was to associate an integrated management system with the last word goal that each becomes a self- funding and property enterprise (Tewodros, 2008).

Though Kaffa forest was selected as "Bonga Natural Forest Priority space (BNFP) (Henok, 2007), then National Forest Priority Area (NFPA) in 1987 by the Ethiopian government but unlike the 1980s, where forest administration was centralized and highly managed by the government, in the 1990s the concept of state- community joint forest management gives the local forest user open access to the forest; consequently, forest resources belong to the State de jure, but they are de facto open access for all sorts of exploitation. Hence, a tremendous amount of forest has been degraded in the 1990s. (Dereje and Mulugeta, 2019). Visible of this, a research project has recently been conducted in Kaffa forest by the biological science analysis Centre on the extent of forest conversion and historical land cowl changes. Supported by remote sensing knowledge and surveys on the undersurface, the results reveal that natural forest in the Kaffa zone has shriveled by twenty- 
one percent throughout the number of forest loss from 1973-1987, by $14.0 \%$ throughout 1987 2001 and decrease of $3 \%$ throughout 2001-2007 (Van Bommel and Van der, 2013). Though this variety showed a reduction of deforestation on the natural forest of Kaffa zone, deforestation at intervals the study Woreda, particularly on non-PFM sites increasing from time-to-time and reducing in PFM sites although it is continued on sort of PFMs sites like Yecha and Angiyo kola kebeles Kaffa Zone Agriculture and Rural Development (KZARD, 2017). To cut back this devastation, per the data collected from Addiyo Woreda Agriculture and Rural Development department, at intervals the Addiyo Woreda, solely 10 PFM (Participatory Forest Management) sites are established between the periods from 2004 until 2009 by completely different organizations covering a whole space of regarding 20,094 ha of forest space. However, members were not adequately organized themselves in these PFM sites as Cooperatives or Forest user Groups (FUG) to sustain PFM (Ibid). As Sisay (2007) cited, the recommendation created by the external consultants commissioned to determine the pilot program that outlined PFM as a result of the sole tool for the management of forest priority areas wherever social, economic and environmental issues may even be self-addressed in accordance to property forest management and suggest replication of the identical elsewhere at intervals the country. Therefore PFM was introduced as one of the solutions to solve the problem of open access to forest resources and promote sustainable forest management in the country through community participation (Gobeze et al., 2009). And also, Winberg (2010) confirms that PFM is a new paradigm system of forest management that is adopted and implemented to fulfill the interest, respecting of traditional users, and bottom-up approach, which encourages a sense of belongingness to the rural people in general landless rural youth in particular. Thus, the main objectives of this research were contributed to assess the factors that challenge public involvement in sustainable participatory forest management in selected kebeles of Addiyo district Kaffa zone, SNNPRs.

\section{METHODS AND METHODOLOGY}

\subsection{Explanation of the Study Area}

This study remained conceded out in three selected kebeles in Addiyo woreda, namely Mera, Angiyo, Kolla, and Yecha. Therefore, it is important to describe briefly Addiyo woreda.

\subsubsection{Astronomical \& relative location of addiyo woreda}

Astronomically Addiyo woreda lies between $7^{\circ} 8^{\prime}-7^{\circ} 26^{\prime} \mathrm{N}$ latitude and $36^{\circ} 15^{\prime}-36^{\circ} 50^{\prime} \mathrm{E}$ longitude (Figure 1) and which is located at the eastern part of Kaffa Zone with the distance of $64 \mathrm{~km}$ from the capital of Kaffa Zone Bonga; $524 \mathrm{~km}$ from the Capital City of Ethiopia and $801 \mathrm{~km}$ from Hawassa. It shares boundaries with Decha Woreda in the West, Gimbo Woreda in the North West, Tello Woreda in the South, Konta special Woreda in the South East, and the North and NorthEastern part with Oromia region Jimma. (KZoFED, 2018). 


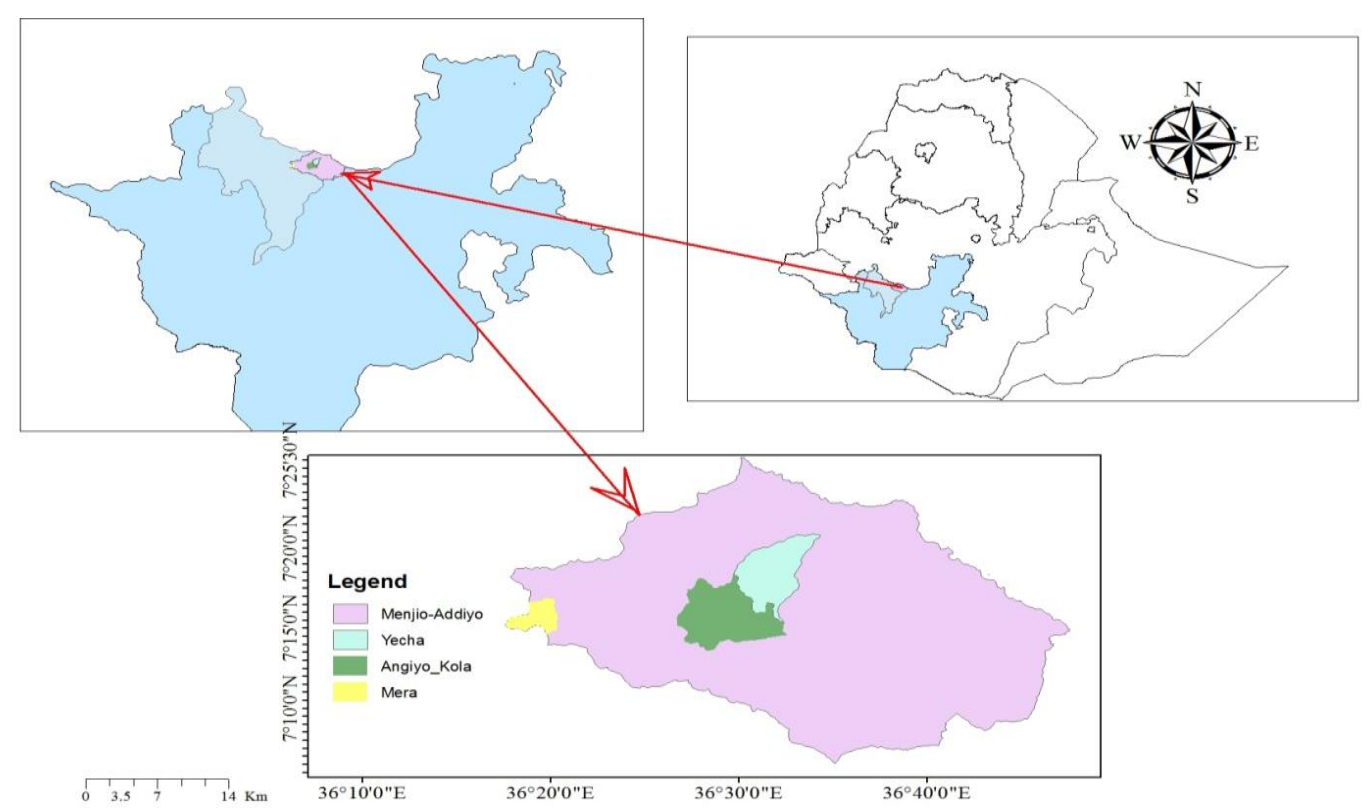

Figure 1: Location Map of the study area made from Arc GIS by researcher, 2018

\subsubsection{Climatic condition}

A comparatively reasonable air situation categorizes it with mean yearly rain fluctuating among 1400 and $2000 \mathrm{~mm}$ and usual annual temperature varying from $12{ }^{\circ} \mathrm{C}$ to $26^{\circ} \mathrm{C}$.

\subsubsection{Vegetation}

According to AWARDO (2018), the study area is covered by forest comprising a rich mixture of species such as indigenous tree specious like Yinoo, Orooroo, Tikur inchet, wolkif (shawuko), Dokima(Yino), Birbira(bibero), Qato, Komo Dido, Bissana (Croton Macrostochys), Kontir (Petrolobium Stellatum), Korch (Erythrinia Abyssinica), Endod(Phytolacca dodecader), Grawa (Vernonia specious), Timiz, Zigba (Podocarpus talacta), Di'oo, Shinaatoo, Cactus and Kerero(Aningeria) are common tree specious and shirubs are also common around kola. Out of which, kosso and Woyira locally have medicinal value.

\subsection{Research design}

This research employs a mixed approach of both quantitative and qualitative methods. Because in a mixed approach, quantitative and qualitative techniques are mixed in a single study, and it is important for seeking convergences and corroboration of results from different methods and designs studying the phenomena. A sequential explanatory research design was used in this study. Quantitative and qualitative data were collected in the form of surveys, questionnaires, semistructured interviews, and focus group discussions that were served to investigate the Challenges Facing the Community Participation on Participatory Forest Management.

\subsection{Sample size and sampling procedures}

Various sampling procedures have been employed in the study of this research. First nonprobability sampling, mainly purposeful sampling technique, has used to choose Addiyo Woreda among ten rural Woreda and 1 City administration of Kaffa zone. The researcher has selected this woreda for different reasons. The reasons are: first, the area has a little bit better practice of PFM with their challenges of community participation. Second, the Addiyo woreda has large-scale deforestation than compared with other woredas of the zone (KZARD, 2017). The third reason is, this woreda has traditionally marginalized groups (Menja) who are mainly depending on the forest for their livelihood. The other point for the selection of this woreda was it contains 28 kebeles. However, the 
emphasis was given only for three kebeles with various cases, including financial and time gaps. Among 28 kebeles, three kebeles were selected for this research, namely, Yecha, Angiyookola and Mera kebeles. To select these three kebeles, a purposeful sampling technique was used because the researcher believed that these three sample kebeles were adequate and representative of the total kebeles in the Woreda. The sampling frame includes all the families in these three, including both household groups that were participants and nonparticipants of PFM. However, a special emphasis has been given to the participants of PFM, because they have expected as had more experience than the nonparticipants. Here, the total number of households in these three kebeles is 1131. In a survey-type investigation, studies regularly have bigger samples because the proportion of responses normally occurs to be low, as low as 20 to $30 \%$, especially in mailed survey studies (Kothari, 1990). Based on this, $25 \%$ of the total population was used as the sample size.

Therefore, $\quad \mathrm{n}=(25 \%$ of $\mathrm{N})=(0.25 * \mathrm{~N})=\left(0.25^{*} 1131\right)=282.75 \approx 283$

\subsection{Data analysis}

The survey generated both qualitative and quantitative data was summarized, categorized and coded some qualitative responses into numeric values and then entered into the statistical program (StataIc11) and Microsoft window (2007). Information obtained from unstructured interviews and informal interviews with key informants and with focus group discussion in the study area was narrative and qualitative. It is used to support coded qualitative and quantitative data. Descriptive statistics, sum, mean, standard deviation, cross-tabulation, and percentages were presented in tables, graphs to enable easy interpretation and quick visual comparisons of variables within the study area. Moreover, Binary logistic regressions remained employed to evaluate factors affecting the participation of households in PFM. T-test and chi-square tests were also used to explore the relationship between independent variables with dependent.

\section{RESULT AND DISCUSSION}

\subsection{Factors that affecting sustainable participatory forest management}

In this subsection of the study, analysis of participation in PFM was discussed using demographic, social, economic, and biophysical variables, and they were analyzed one by one to identify their relationship with the dependent variable, i.e., probability of participation in PFM.

\subsubsection{The binary logistic regression analysis for probability of participation in PFM}

In the previous section, variables describing the probability of participating in PFM and their differences between the participants and nonparticipant households are recognized. Though, within the binary logistic model investigation, the study emphasizes seeing the joint results of variables among contributors and non-contributors inn the study area. All variables related to the probability of participation in PFM binary logistic regression are mentioned the $p$ values, with the worth of $\mathrm{P}<0.01$ and $\mathrm{P}<0.05$. Therefore, those variables which were identified as statistically significant have not multi-colinearity effect. The outputs of the logistic model were predicted using logistic state command to get the output with the odds ratio described below.

Between 10 variables included in the model, the Wald $\mathrm{X}^{2}$ te st results for 8 of them show that they are found to be statistically substantial and had important relationships with the chance of involvement in PFM (Table 1). The result of the logistic regression analysis shows that family size, annual income, number of livestock support, and distance of PFM site in km were statistically important at a $1 \%$ significance level.

Income from the forest, awareness of household respondents on PFM, and distance from the market remained as well statistically substantial at a 5\% significance level. 
Table 1: Binomial logistic regression (reporting odds ratio) of participation in PFM

\begin{tabular}{|c|c|c|c|c|c|c|c|}
\hline \multirow{2}{*}{ Partcip } & \multirow{2}{*}{ Coef. ( $\beta$ ) } & \multirow{2}{*}{$\begin{array}{c}\text { Odds Ratio } \\
\left(\mathbf{E X P}^{(\mathbf{B})}\right)\end{array}$} & \multirow{2}{*}{$\begin{array}{c}\text { Robust } \\
\text { Std. Error }\end{array}$} & \multirow{2}{*}{$\mathbf{Z}$} & \multirow{2}{*}{$\begin{array}{l}\text { Sig. } \\
(\mathbf{P}>\mathbf{z})\end{array}$} & \multicolumn{2}{|c|}{ [95.0\% Confidence Interval] } \\
\hline & & & & & & Lower & Upper \\
\hline Famsize & 0.732 & 2.079 & 0.664 & 2.29 & $0.022 * *$ & 1.111 & 3.891 \\
\hline _IEduc_1 & -1.831 & 0.160 & 0.184 & -1.59 & 0.112 & 0.016 & 1.533 \\
\hline _IEduc_2 & -2.277 & 0.102 & 0.128 & -1.82 & 0.069 & 0.008 & 1.193 \\
\hline _IEduc_3 & -1.192 & 0.303 & 0.313 & -1.15 & 0.248 & 0.040 & 2.297 \\
\hline IMarstatu 1 & -2.676 & 0.068 & 0.121 & -1.52 & 0.129 & 0.002 & 2.175 \\
\hline Anincom & -.5167 & 0.596 & 0.086 & -3.57 & $0.000 * * *$ & 0.448 & 0.792 \\
\hline forIncome & 0.0003 & 1.000 & 0.0002 & 2.37 & $0.018 * *$ & 1.000 & 1.000 \\
\hline Livestock & 0.744 & 2.104 & 0.430 & 3.64 & $0.000 * * *$ & 1.409 & 3.142 \\
\hline _IAware_1 & 2.356 & 10.558 & 11.215 & 2.22 & $0.026 * *$ & 1.316 & 84.673 \\
\hline ISupport_1 & 4.930 & 138.430 & 167.578 & 4.07 & $0.000 * * *$ & 12.906 & 1484.79 \\
\hline Hmuinhrs & -1.094 & 0.334 & 0.119 & -3.07 & $0.002 * * *$ & 0.166 & 0.673 \\
\hline Hmuinhmr & -0.845 & 0.429 & 6.065 & -2.01 & $0.044 * *$ & 0.188 & 0.978 \\
\hline Cons & -0.693 & - & 2.000 & -0.35 & 0.729 & -4.614 & 3.227 \\
\hline
\end{tabular}

Note: $* * *$ and $* *$ indicate $1 \%$ and $5 \%$ level of significance respectively

Number of observations $=295$, Pseudo R-Square $=0.8654$, Wald Chi ${ }^{2}(12)=53.32$, Prob $>\mathrm{Chi}^{2}=0$

$-2 \log$ likelihood value $=-26.719, \%$ of correct prediction for participants $=96.61 \%(171$ households out of

$177), \%$ of correct prediction for non- participants $=94.92 \%(112$ households out of 118$)$

$\%$ of total correct prediction $=95.93 \%(283$ households out of 295$)$

Source: Survey data, 2018

Moreover, annual income, space from the forest, and remoteness from the market had a negative correlation; the rest were found to have a positive correlation with participation on PFM. However, education level [ $\left(1^{\text {st }}\right.$ of primary education cycle $),\left(2^{\text {nd }}\right.$ cycle of primary education), (secondary education), and (above secondary (complete)] and marital status were found to be insignificant at $5 \%$ significance level.

Even though the level of education is insignificant at fewer than 5\% significance level, the negative coefficient indicates that households who have less educational level are more likely to participate in PFM than those who have more educational level. It is in line with that an advanced level of education offers an extensive choice of work possibilities; hereafter, income from the woodland product is nonpaying due to bigger opportunity costs of forest product (Dolisca et al., 2006). However, the study that was founded by Coulibaly-Lingani et al. (2009) and Musyoki et al. (2013) exposed that the level of schooling did not have a relation with the level of involvement in forest management.

In the same way, even though marital status was insignificant at less than a 5\% significance level and hypothesized as have a positive correlation, the negative coefficients indicate that marital status has an inverse relation with PFM. However, the study result of Temesgen (2007) displayed that single people associated with the married ones have inadequate knowledge of ecological management since people get married; they encompass more in community activities than the lone person.

\subsubsection{Interpretation of odds ratios}

Those variables that were found statistically significant were interpreted using the odds ratio as follows: 


\subsubsection{Awareness of households about PFM}

Logistic regression results revealed that the awareness level of the household on the PFM has an optimistic relationship with membership on PFM at a 5\% level of significance $(B=2.356, P<0.01)$. The positive Beta value shows that there is a direct relationship of awareness of respondents about PFM with participation in PFM. The result revealed the odds ratio related to consciousness of household head on PFM [OR=10.558, 95\% C.I: $(1.316,84.673)]$. It can be interpreted as holding all other sovereign variables constant in the model; an odds ratio of 10.558 is in the indulgence of involvement on PFM by way of households who have awareness on PFM than those who have no consciousness on PFM.

It implies that household who had an awareness of participatory forest management, his/her awareness makes the household clearly understand to join and benefit from the PFM. This is in line with the study that signifies involvement in PFM activities will probably depend on community responsiveness as informed by Alves et al. (1999), who decided that attentiveness on terrestrial deprivation and insight of the assistances to be improved out of the forest management does are critical issues for asset and agreement of conservation measures. Other studies also have shown a similar result; the level of awareness of the household head by education has a positive effect on on-farm tree planting. People who are more granted have more income opportunities (Thalma et al., 2018).

\subsubsection{Support of external stakeholders}

Based on the logistic regression end in the damage of household on the PFM includes a positive relationship with participation on PFM at a $1 \%$ level of consequence $(\beta=4.930, \mathrm{P}<0.01)$. The positive Beta value shows that there is a direct relationship of support from external stakeholders and participation in PFM. The logistic result revealed that the chances ratio related to support of external stakeholders for PFM [OR=138.430, 95\% C.I: $(12.906,1484.79)]$. It could be taken as holding all additional independent variables are constant within the model; an odds ratio of 138.430 is in approval of involvement on PFM as per the support of external stakeholders applied on PFM than not. It suggests that those households who got support for participatory forest management better to affix to PFM. The main focus conference also revealed that, the households needs support to conserve their forest, one among the group member stated that, "after PFM was established in our kebele those external stakeholders not visiting, providing support including technical, financial yet as materials except in the future support of potato. And the shortage of external stakeholders' support is not good if we are visiting to create sustainable PFM because we have no alternatives to use. Unless we get support from the government and other alternative bodies, it is very hard since our life is betting on forest. This discussion is in line with the study of Clare (2010), stated that a high level of involvement from a large range of external actors or stakeholders would increase the likelihood of sustainable collective action in joint forest management (JFM) at the local level.

\subsubsection{Annual income of the households}

The logistic regression result reveals that an annual income and participation in PFM has a statistically weighty relationship at a $1 \%$ level of consequence and negative relationship $(\beta=-$ $0.516, \mathrm{P}<0.01)$. The negative Beta value shows that there is an inverse relationship between household annual income and participation in PFM. Annual income has the chances ratio of $[\mathrm{OR}=0.569$, 95\% C.I: $(0.448,0.792)]$. The result may be inferred holding all other variables persistent; the chances ratio of 0.569 is in disfavor of participating in PFM as the annual income of household increases by one unit in Birr. It means that there is less probability of participation in PFM because of the annual income of households increases. Accordingly, on the average value of annual income, when annual income increase by one Birr from average annual income (8269.15Birr ), the probability of participation of household in PFM decreases by a marginal factor of 0.049 . 
Information gathered from FGD and key informant interviews revealed that people who have an improved annual income do not seem interested to participate in PFM because they endure their activity instead of becoming a PFM participant and to be benefited from PFM. It could be households who have more annual income might not be interesting to hitch in PFM because they need a sufficient yearly income to shop for forest products. Annual income could be a substantial feature for the public to receive and take part in communal resource administration (Shahbaz and Ali, 2006). However, opposite studies whose investigations were conducted by Kugonza (2009) has recommended the lack of a connection amongst involvement in shared resource administration and yearly revenue of households. Within the same way, an inquiry conducted by Chhetri (2005) in Nepal also does not illustrate any significant association between public involvement and yearly income.

\subsubsection{Income from forest}

Logistic regression leads to revealing that forest income and participation in PFM has a significant relationship at $5 \%$ of significance and positive relationship $(\beta=2.28 * 10-4, \mathrm{P}<0.05)$. The positive Beta value shows that there is a direct relationship between household income from forest and participation in PFM. Income from forest has the chances ratio of [OR=1, 95\% C.I: (1.000048, 1.000623)]. The result may be understood allotment all other variable constant, the percentages ratio of 1.000 is in the indulgence of involvement in PFM as income from the forest of household increases by one unit of Ethiopian currency (Birr). It means that there is more probability of participation in PFM because of the forest income of households increases. Accordingly, on the average value of forest income when income from forest increase by one Birr from the average value of income from the forest (4747.92Birr), the probability of participating household in PFM increases by a marginal factor of $2.73 * 10-5$. When an individual produces abundant income since woodlands contain an astonishing chance to urge contributed to PFM. From FGD, one amongst the members stated that "I saw forest over my son, this can be because I generate my income from the forest and use for my family's daily expenditure, so I have got no life if there is no forest. Therefore, I am so interested in conserving my forest and in getting more income from it." This investigation result is in a step with Alemtsehay (2010), and it suggests that the number of forests has powerfully exaggerated on specific choices whether to partake or not within the administration of a typical reserve. Per Gebremdhin (2008) suggests, the possibility to partake in PFM rises suggestively because the fiscal welfares one might produce as of PFM growths additionally. Faham et al. (2008), in their research in Iran, furthermore specified that monetary drive and forest dependence are certainly and meaningfully associate with forest occupants' involvement in the expansion of forest areas. Contrary to the above discoveries, a pursuit piloted by Kugonza (2009) in the Northwestern a part of Uganda recommends that respondent's requirement on forest properties have not any substantial effect on preparedness to join in public grounded woodland administration.

\subsubsection{Number of livestock}

From the logistic regression, the end in the number of livestock and participation in PFM has a statistically important relationship at a $1 \%$ level of significance and positive relationship $(\mathrm{B}=$ $0.743, \mathrm{P}<0.01$ ). The positive Beta value shows that there has a positive relationship between the household figure of cattle and participation in PFM. The number of cows has the chances ratio of $[\mathrm{OR}=2.104,95 \%$ C.I: $(1.409,3.142)]$. The result is interpreted holding all other variables persistent; the possibilities proportion of two.104 is in favor of participation in PFM. As the kind of livestock of households increases by one unit, which is measured in the tropical livestock unit (TLU), the probability of participation of households in PFM increases by a marginal factor of 0.072 . It means that folks who have more numbers of livestock more probability participate in PFM than people who have less livestock. The key interview and FGD also indicate that those households who have higher livestock are more interested in using fodder or grass and wish materials from this forest to form an element for keeping their livestock. The following study results are in line with this study result, and livestock capitals of households were well-thought-out by many researchers as a contributing factor to take in in protection of forest resources. A numerical investigation steered in 
Nepal endorses that family with a sizable amount of cattle features a high possibility to join in in participatory woodland administration than their particular complements (Chhetri, 2005). And also, the research by Agrawal and Chatre in three Indian states, who used an econometrical model and recommend that family administrators' cattle money are powerfully and certainly connected with the participation in defense and growth of woodland capitals (Agrawal and Chatre, 2006).

\subsubsection{Family size}

Based on logistic regression result, family size and participation in PFM has a statistically weighty relationship at a $5 \%$ level of significance and positive relationship $(\beta=0.731, \mathrm{P}<0.05)$. The positive Beta value shows that there has a positive relationship between family size and participation in PFM. Family size has the possibilities ratio [OR=2.079, 95\% C.I: $(1.111,3.89)]$. The results are often interpreted, keeping all other variables relentless; the possibilities share of 2.079 is in favor of participation in PFM as the family size of household increases by one unit, the probability of participation of household in PFM increases by a marginal factor of 0.708 . It means that there has more probability of participation in PFM as the family size of households increases. Due to the large family size, there is a shortage of own enough resources but a chip labor source. Therefore, so hide this problem, they interest to hitch in PFM and to use different and better technology, which is provided by different external stakeholders if they supply and conserve their environment. Massive children can rally state of plantation by growing collective family heads offerings to up keeping and provision to organizations that ease maintenance.

Furthermore, such families contributing to PFM and cashing in wood products may be viewed as a viable livelihood alternative for the larger family sizes. Large kin adopts labor-intensive technology and thus contribute plenty to the event of wearing (Tiffen et al., 1994).

\subsubsection{Distance from PFM site}

Logistic regression revealed that distance of participatory forest management site from household respondents has a statistically significant affiliation with involvement in PFM at a $1 \%$ level of significance and negative relationship $(\beta=-1.094, \mathrm{P}<0.01)$. The negative Beta value shows that there is an inverse relationship of household distance in minutes from PFM forest and participation in PFM. The distance of PFM forest has the odds ratio [OR=0.334, 95\% C.I: $(0.166,0.673)]$. The result can be understood, holding all additional variables constant, the odds ratio of 0.334 is in disfavor of participating in PFM as the distance of household increases by one unit (kilometer). It indicates that there is less probability of participation in PFM as the distance of households from PFM forest increases. Accordingly, on the average value of distance, when distance increase by one kilometer from an average distance of 2.65 kilometers, the probability of participation of households to participate in PFM decreases by a marginal factor of 0.105 .

This negative relation indicates that to arrive in the PFM forest, it may need transportation and when the transportation cost rises with remoteness and consequently develops more affluent, exclusively because their actions linked to guard the woodland wants additional of their consistent occurrence. FGD results from both sites also revealed that it is difficult to take a walk and to pay for transportation costs from time to time. Rather, one of the non-participant members said, even it is better to help in the form of cash by voluntarily rather than to come and join the PFM because forest protect will be useful for our environment.

The studies in line with this were found from Thoai and Ranola (2010) showed that there is a contrary connection among the distance of the home of the agrarian from the forest extent to be accomplished and the possibility of involvement. The larger the overlap between the location of common-pool resources and the residence of the users, the greater the chance of success (Wade, 1987). Moreover, Chhetri (2005) and Kugonza (2009) found a negative relationship between distance from forest and community involvement in forest protection. In divergence to this, the 
study reveals that distance is not a determining factor in the household choice to partake in forest management (Musyoki et al., 2013).

\subsubsection{Distance from market}

The distance of the market and participation in PFM has a "statistically significant" relationship at a $5 \%$ level of "significance" and a negative relationship $(\beta=-0.845, \mathrm{P}<0.05)$. The negative Beta value indicates that there is an inverse relationship between the distance of the market and participation in PFM. The distance of market has the odds ratio of $[\mathrm{OR}=0.429,95 \%$ C.I: $(0.188$, $0.978)$ ]. The result "can be understood holding all other variables constant, the odds ratio" of 0.429 is in disfavor of partaking in PFM as the distance of the market of household increases by one unit (kilometer). It indicates that there is less probability of participation in PFM as the distance of households from the market center increases. Accordingly, on the average value of distance, when the distance from the market center increase by one kilometer from an average distance of 1.8 kilometers, the probability of participation of households to participate in PFM decreases by a marginal factor of 0.081 . It indicates that there is more probability of participation in PFM when the market center is nearby the PFM site. Interviewees who are very close to the market are expected to join PFM at the earliest. It is because they can effortlessly sell the forest harvests and support their livelihood.

FGD of both sites also revealed and agreed that "it is necessary for those households who live in the nearby market at the same time by PFM forest to participate because we could easily access the market to sell our forest products."

Remoteness to the market from the household's home has a significant adverse effect on involvement in forest resource exploitation Bedru (2007). In contrast to this, researchers who are in substantial works on the influence of transportations and markets initiate a positive relationship between distance from the market and management of forest (Agrawal and Chhatri, 2006).

\section{CONCLUSION}

The majority of the community, both participants and non-participants do not have the consciousness to maintainable participatory forest managing plus future dangers of forest depletion. The status of woodland in the locality still decreasing, whereas income from the forest is increased; Lack of awareness, distance from PFM forest, feeling that PFM losses forest use right and no trust on PFM are hindering factors for non-participants not to join in PFM. The Source of fuel for household consumption is only from forest and forest products. There is no lively hood diversification done for the community to reduce reliance on the forest. The benefit distribution is varied among participants. In general, the majority of respondents agree that PFM is more significant than the traditional forest conservation system.

Funding: This study received no specific financial support.

Competing Interests: The authors declare that they have no competing interests.

Contributors/Acknowledgement: The author would like to thanks Addiyo woreda for his help during the data collection, his brother Dagne Alemayehu and all his friends and household heads, who helped to design and organize this research.

Views and opinions expressed in this study are the views and opinions of the authors; the Asian Journal of Agriculture and Rural Development shall not be responsible or answerable for any loss, damage or liability, etc. caused in relation to/arising out of the use of the content.

\section{References}

Agrawal, A., \& Chatre, A. (2006). Explaining success on the commons: community forest governance in the Indian Himalaya. World Development Journal 34(1), 149-166. https://doi.org/10.1016/j.worlddev.2005.07.013. 
Alemtsehay, J. (2010). Determinating factors for a successful establishment of participatory forest management: a comparative study of Goba and Dello districts, Ethiopia. MA Thesis. University of Agder, Kristiansand, Norway.

Alves, D. S., Pereira, J. L. G., de Sousa, C. L., Soares, J. V., \& Yamaguchi, F. (1999). Characterizing landscape changes in central Rondonia using Landsat TM imagery. International Journal of Remote Sensing, 20, 2877-2882.

Asfaw, Z., \& Fekadu, B. (2018). Factors affecting smallholder farmers' participation in degraded forest rehabilitation practices. the case of Gemachis district, West Hararghe Zone, Oromia region. Ethiopia Journal of Agricultural Extension and Rural Development, 10(11), 234244 ,

Bedru, B. (2007). Economic valuation and management of common pool resources. The case of enclosures with the highlands of Tigray, Northern Ethiopia. Ph.D. Dissertation. The Catholic University of Leuven.

Chhetri, K. (2005). Community forestry program with the hills of Nepal: determinants of user participation and household dependency. MSc Thesis. Norwegian, University of Life Sciences (UMB), Norway.

Clare, B. (2010). Sustainable collective action in joint forest management, Maharashtra, India. MSc Thesis submitted to Utrecht University.

Coulibaly-Lingani, P., Tigabu, M., Savadogo, P., Oden, P. C., \& Ouadba, J. M. (2009). Determinants of access to forest products in southern Burkina Faso. Forest Policy and Economics, 11(7), 516-524. doi.org/10.1016/j.forpol.2009.06.002.

Dereje, M., \& Mulugeta, A. (2019). Community based participatory forest resources management practices in Chilimo forest, Dendi district, West Shewa Zone, Oromia regional state, Ethiopia. African Journal of Agricultural Research, 14(35), 2119-2134. doi.org/10.5897/ajar2019.14389.

Dolisca, F., Carter, J., Daniel, D., Shannon, A., \& Jolly, M. (2006). Factors Influencing Farmers Participation in Forestry Management Programs: A case study from Haiti. Forest Ecology and Management, 236(3), 324-331.

Faham, E., Rezvanfar, A., \& Shamekhi, T. (2008). Analysis of socio-economic factors influencing forest dwellers' participation in reforestation and development of forest areas (The Case Study of West Mazandaran, Iran). American Journal of Agricultural and Biological Sciences, 3(1), 438-443.

Fisher, R. (1999). Decentralization and development of forest management in Asia and the Pacific. International Journal of Forestry and Forest Industry, 50(99), 3-5.

Gebremdhin, A. (2008). Determinants of success of participatory forest management (PFM). The case of WAJIB approach in Ethiopia. MSc Dissertation. Institutes for Environmental decision, Ethiopia.

Gobeze, T., Bekele, M., Lemenih, M., \& Kassa, H. (2009). Participatory forest management and its impacts on livelihoods and forest status: the case of Bonga forest in Ethiopia. International Forestry Review, 11(3), 346-358. doi.org/10.1505/ifor.11.3.346.

Henok, W. (2007). Practices and the Challenges of Participatory Forest Management in Ethiopia: The Case of Bonga Participatory Forest Management Scheme, SNNPRS. Unpublished Thesis. University of Addis Ababa, Ethiopia.

Islam, K. K., Rahman, G. M., Fujiwara, T., \& Sato, N. (2013). People's participation in forest conservation and livelihoods improvement: experience from a forestry project in Bangladesh. International Journal of Biodiversity Science, Ecosystem Services \& Management, 9(1), 30-43. doi.org/10.1080/21513732.2012.748692.

Kaffa Zone Agriculture Rural Development (KZARD). (2017). Kaffa zone agriculture rural development annual report. Bonga: KZARD.

Kaffa Zone Finance and Economic Development (KZoFEd). (2018). Kaffa zone finance and economic development annual report: statistical abstract. Bonga: KZoFEd.

Kanel, K., \& Dahal, G. (2008). Community forestry policy and its economic implications: an experience from Nepal. International Journal of Social Forestry, 1(1), 50-60. 
Khanal, K. P. (2007). Participatory Forestry and its Contribution to the Livelihood of Rural Poor. In: Kelbessa, E. and De Stoop, C. (eds.) Participatory forest management (PFM), Biodiversity and livelihoods in Africa. Proceedings of the International Conference, 19-21 March 2007. FARM Africa/SOS Sahel, Addis Ababa, Ethiopia. 54-61 pp.

Kothari, C. (1990). Research methodology: Methods and techniques (2 $2^{\text {nd }}$ ed.). India: New Age, International.

Kugonza, A. (2009). Linking local community's livelihood and forest conservation in Masindi district, North Western Uganda. Research Journal of Applied Science 4(1), 10-16.

Musyoki, J. M., Kennedy, M., \& Mbae, M. (2013). Determinants of household decision to join community forest associations: a case study of Kenya. ISRN Forestry, 1-11.

Shahbaz, Z., \& Ali, T. (2006). Participatory Forest Management. In Troubled Times: Sustainable Development within the Age of Extremes. Sustainable Development Policy Institute (SDPI), Islamabad, Pakistan: 148-158p.

Shindler, B., \& Cramer, L. A. (1999). Shifting public values for forest management: Making sense of wicked problems. Western Journal of Applied Forestry, 14(1), 28-34. doi.org/10.1093/wjaf/14.1.28.

Sisay, N. (2007). Proceedings of a national workshop on policies to increase forest cover in Ethiopia: Ethiopian government efforts to increase forest cover from 18-19 September 2007. Organized by environmental economics policy forum for Ethiopia (EEPFE and Ethiopian Development Research Institute (EDRI), Addis Ababa, Ethiopia.

Stellmacher, T. (2007). Governing the ethiopian coffee forests: an area-level institutional analysis in kaffa and bale mountains. $\mathrm{PhD}$ Dissertation. Institute for Lebensmittel- und Ressourcenökonomik (ILR). Bonn.

Temesgen, K. (2007). Analysis of environment of coverage in Addis Zemen Amharic daily newspaper. Master's Thesis. Addis Ababa: Addis Abba University. Third Edition, England: Open University press.

Tewodros, W. (2008). Factors Affecting the Knowledge, Attitude and Practice of Forest Dependent Manja Community Towards Forest Conservation. For the case of Kaffa Zone, SNNPRs. MA Thesis. University of Addis Abeba, Ethiopia.

Thalma, K., David, L., Paul, A., \& Samson, O. (2018). Factors Influencing Adoption of on-Farm Tree Planting in Shinyalu Sub-County, Kakamega, Kenya. International Journal of Forestry and Horticulture (IJFH) 4(3), 38-48. DOI: http://dx.doi.org/10.20431/24549487.0403006 www.arcjournals.org.

Thoai, T. Q., \& Ranola, R. F. Jr. (2010). Decision making by upland farmers on forest management in the northwest mountainous region of Vietnam. Journal of International Society for Southeast Asian Agricultural Sciences Vol. 16, No. 1:68-82p

Tiffen, M., Mortimore, M., \& Gichuki, F. (1994). Population growth and environmental recovery: Policy lessons from Kenya. Gatekeeper Series No. 45, London: International Institute for Environment and Development.

Van Bommel, S., \& Van der, Z. (2013). Creating Scientific Narratives: Experiences in Constructing and Interweaving Empirical and Theoretical Plots Publisher: Springer DOI: 10.1007/978-94-007-5113-2 11 In book: Forest and Nature Governance: A Practice Based Approach (pp.217-239)

Wade, R. (1987). Village republics: economic conditions for collective action in South India. Cambridge: Cambridge University Press. Forthcoming.

Winberg, E. (2010). Participatory forest management in Ethiopia, practices and experiences. Addis Ababa: Food and Agriculture Organization, Sub-regional Office for Eastern Africa (SFE). http://www.fao.org/forestry/24514043adbe564e803444b40d3e18987b434d.pdf.

Zewdie, Y. (2002). Access to forest resources and forest-based livelihoods in highland of Kafa, Ethiopia: A Resource Management Perspective. Ph.D. Dissertation. University of Huddersfield, England. 